\title{
Cerebrospinal Fluid Biomarkers as Predictors of Shunt Response in Idiopathic Normal Pressure Hydrocephalus: A Systematic Review
}

\author{
Tyler Pfanner, Alexandre Henri-Bhargava, Stephanie Borchert
}

\begin{abstract}
Background: The widely accepted treatment for idiopathic normal-pressure hydrocephalus (iNPH) is a cerebrospinal fluid (CSF) diversion shunt procedure, to which approximately $80 \%$ of patients will respond. The purpose of this systematic review was to identify which CSF biomarkers have been investigated in predicting shunt responsiveness in iNPH patients, and to analyze the level of evidence for each. Methods: To find all relevant articles, a comprehensive search of Medline, Embase, and PsycINFO was conducted. Results: The literature search identified 344 unique citations, of which 13 studies satisfied the inclusion criteria and were analyzed in our review. These 13 studies reported on 37 unique biomarkers. Conclusions: The available studies suggest that there is evidence for the utility of CSF biomarkers in predicting shunt responsiveness in iNPH patients, though none have been shown to predict shunt response with both high sensitivity and specificity. We found that there is no available evidence for the use of A $\beta 38$, A $\beta 40$, A $\beta 43$, APL1 $\beta 25$, APL1 $\beta 27$, APL1 $\beta 28$, sAPP, aAPP $\alpha$, sAPP $\beta$, TNF- $\alpha$, MCP-1, sCD40L, sulfatide, MBP, L-PGDS, cystatin C, transthyretin, TGF- $\beta 2$, or YKL-40 in predicting shunt response. There is minimal evidence for the use of TGF- $\beta 1$, TBR-II, homocysteine, and interleukins (particularly IL- $1 \beta$, IL-6, and IL-10). However, the available evidence suggests that these biomarkers warrant further investigation. A $\beta 42$, tau, p-tau, NFL, and LRG have the greatest amount of evidence for their predictive value in determining shunt responsiveness in iNPH patients. Future research should be guided by, but not limited to, these biomarkers.
\end{abstract}

RÉSUMÉ: Revue systématique du rôle prédicteur de la réponse à une dérivation au moyen de bio-marqueurs du liquide céphalo-rachidien : les cas de patients atteints d'hydrocéphalie à pression normale de type idiopathique. Contexte: Le traitement le plus communément admis pour l'hydrocéphalie à pression normale de type idiopathique (HPNi) est d'utiliser du liquide céphalo-rachidien (LCR) à l'aide de tubes ou de drains de dérivation (shunt), intervention à l'égard de laquelle environ $80 \%$ des patients répondent positivement. L'objectif de cette revue systématique a donc été d'identifier les bio-marqueurs du LCR aptes à prédire une telle réponse et analysés au fil des années et d'évaluer leur validité en fonction des preuves. Méthodes: Pour repérer tous les articles pertinents sur le sujet, nous avons effectué une recherche exhaustive à l'aide des bases de données suivantes : Medline, Embase et PsycINFO. Résultats: Notre recherche documentaire nous a permis d'identifier 344 citations uniques. Au total, 13 études ont satisfait à nos critères d'inclusion et ont été analysées dans le cadre de cette revue systématique. À noter qu'elles ont fait état de 37 bio-marqueurs uniques. Conclusions: Les études disponibles suggèrent que les bio-marqueurs du LCR sont utiles pour prédire la réponse à une dérivation chez des patients HPNi, et ce, bien qu'aucun de ces marqueurs n'a semblé pouvoir prédire une telle réponse de façon très sensible ou spécifique. Pour prédire la réponse à une dérivation, nous avons par ailleurs noté qu'il n'existe aucune preuve qui supporte l'utilisation des bio-marqueurs suivants : A $\beta 38$, A $\beta 40$, A $\beta 43$, APL1 $\beta 25$, APL1 $\beta 27$, APL1 $\beta 28$, sAPP, aAPP $\alpha$, sAPP $\beta$, TNF- $\alpha$, MCP-1, sCD40L, le sulfatide, MBP, L-PGDS, la cystatine C, la transthyrétine, TGF- $\beta 2$ et YKL-40. De plus, il n'existe que de faibles preuves supportant l'utilisation de ces bio-marqueurs : TGF- $\beta 1$, TBR-II, l'homocystéine et les interleukines (en particulier IL-1 $\beta$, IL-6 et IL-10). Toutefois, les preuves dont on dispose indiquent qu'il serait justifié de se pencher de façon plus approfondie sur ces bio-marqueurs. Enfin, A $\beta 42$, t-Tau, p-Tau, NFL et LRG sont tous des bio-marqueurs dont la capacité à prédire la réponse de patients HPNi à une dérivation est supportée par de nombreuses preuves. Ainsi, les travaux de recherche à venir sur le sujet devraient être orientés par ces bio-marqueurs sans nécessairement s'y limiter.

Keywords: Biomarkers, hydrocephalus, neurosurgery, neurology, adult

doi:10.1017/cjn.2017.251

Can J Neurol Sci. 2018; 45: 3-10

From the Faculty of Medicine, University of British Columbia, Vancouver, British Columbia, Canada (TP); Department of Neurology, Island Health, Neurology, Victoria, British

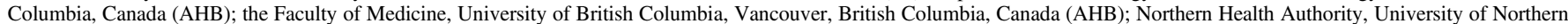
British Columbia, Prince George, British Columbia, Canada (SB).

Received June 1, 2017. Final Revisions Submitted July 31, 2017. Date of Acceptance August 2, 2017.

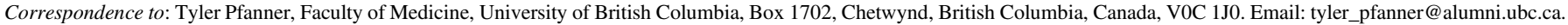




\section{INTRODUCTION}

Idiopathic normal-pressure hydrocephalus (iNPH) is a clinical syndrome consisting of dilated cerebral ventricles along with the clinical triad of gait disturbance, cognitive disturbance (dementia), and/or urinary dysfunction. Cerebrospinal fluid (CSF) diversion through a surgically placed shunt is currently the standard method of treatment. Previously, the diagnosis of iNPH was made based on a positive response to a ventricular shunt, once ruling out possible causes of secondary NPH, such as subarachnoid hemorrhage or meningitis. However, in 2004, the Japanese Society of Normal Pressure Hydrocephalus published the first evidence-based guidelines on the diagnosis of iNPH, ${ }^{1}$ and it was recommended that persons with suspected iNPH be categorized as "definite," "probable," "possible," and "unlikely." The first widely accepted English-language evidence-based diagnostic criteria for idiopathic normal-pressure hydrocephalus were published in $2005^{2}$ and followed the stratified approach of the Japanese guidelines. The Normal Pressure Hydrocephalus guidelines were updated in $2012 .^{3}$

A shunt procedure is indicated for patients who fulfill the criteria of probable iNPH. Approximately $80 \%$ of patients diagnosed with probable iNPH will respond to a shunt procedure. ${ }^{4,5}$ Due to the invasiveness and high adverse event rate $\left(\sim 11 \%^{5}\right)$ of the shunt procedure, a tool to help predict which patients with probable iNPH will respond or not to a shunt procedure would be of clinical value. In recent studies with relatively large numbers of iNPH patients, it was found that no current radiological marker has been shown to predict shunt response with high sensitivity or specificity. ${ }^{6,7}$ The 2012 clinical guidelines for $\mathrm{iNPH}^{3}$ have recognized that there is potential for the use of CSF biochemical tests in the diagnosis and treatment of iNPH; however, the current evidence is not strong enough to recommend a change in clinical practice. With CSF sampling being routine in the diagnosis of iNPH, CSF biomarker analysis would be an extremely low-risk additional investigation.

The present review summarizes the current state of research into using preoperative CSF biomarkers as predictors of shunt response in iNPH patients.

\section{Methods/InClusion Criteria}

To find all relevant articles, a comprehensive text-word search of Medline, Embase, and PsycINFO was conducted. All articles published as of 13 March 2017 were included.

In a preliminary literature search, it was found that shunt responsiveness was rarely a major focus of the currently available research studies and was therefore rarely mentioned in the titles or abstracts of research articles. Because of this, shunt responsiveness was not included in the literature search strategy. The full search strategy is outlined in Appendix 1 (see the Supplementary Materials).

A total of 344 unique citations were identified. All citations were reviewed by two independent reviewers. All discordant conclusions were resolved by a third independent reviewer. Abstract reviews were completed for all citations. Abstracts that made mention of NPH and CSF biomarkers were selected for full-article reviews. Full-article reviews were completed to determine which articles satisfied the following inclusion criteria:

1. must contain an iNPH study group as diagnosed using evidence-based guidelines

2. lumbar CSF biomarker analysis completed
3. shunt-responsive (SR) patients must be reported separately from shunt-nonresponsive (SNR) patients

4. iNPH and sNPH results must not be combined in the analysis

5. must consist of 10 or more iNPH patients

To be included in the review, a study had to specifically mention the inclusion of patients with idiopathic normal-pressure hydrocephalus, as diagnosed using evidence-based guidelines. ${ }^{1-3}$ It has been shown that secondary NPH (sNPH), due to such causes as subarachnoid hemorrhage, meningitis, and traumatic brain injury, has a different CSF protein profile than iNPH. ${ }^{8,9}$ Therefore, studies that combined both idiopathic and secondary NPH when reporting results were excluded. Studies that analyzed ventricular CSF were excluded, as sampling from this area is not considered a routine investigation in the diagnosis of iNPH, and ventricular CSF has been shown to have a different protein profile than lumbar CSF. ${ }^{10,11}$ The studies did not have to have a comparative group, but they had to report patient biomarker concentrations, separated into shunt-responsive and shuntnonresponsive groups. Studies included in this review employed differing definitions of shunt responsiveness, including: any objective or subjective improvement of the iNPH symptom triad, improvement on the Modified Rankin Scale, and improvement in cognition as measured through a Mini-Mental Status Exam. In analysis of the evidence, we highlight these differing definitions and attempt to reconcile them when possible. See Figure 1 for a depiction of the study selection process.

\section{ANALysis OF EVIDENCE}

A total of 13 articles were found to satisfy the inclusion criteria. The quality of evidence in the included articles was ranked according to the American Academy of Neurology Clinical Practice Guidelines. ${ }^{12}$ There were 6 class IV articles, ${ }^{13-18}$ 5 class III articles, ${ }^{10,19-22}$ and 2 class II articles ${ }^{23,24}$ relevant to the prognostic question.

The 13 relevant studies reported data on a total of 508 patients. Of the studies in which relevant patient data were available, the shunt response rate was $78.74 \%$, and the mean age was

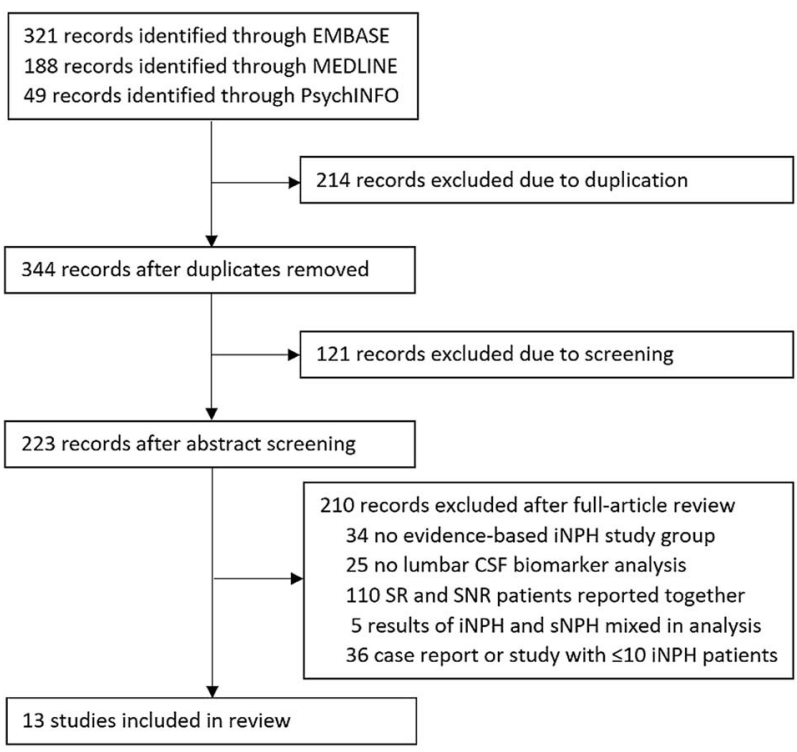

Figure 1: Study selection. 


\section{Table 1: CSF biomarkers analyzed in single studies}

\begin{tabular}{|c|c|c|c|}
\hline Biomarker & Quality of study & Biomarker & Quality of study \\
\hline $\mathrm{A} \beta 43$ & $\mathrm{IIII}^{20}$ & IL-33 & $\mathrm{IV}^{18}$ \\
\hline Cystatin C & $\mathrm{IV}^{13}$ & L-PGDA & $\mathrm{IV}^{13}$ \\
\hline Homocysteine & $\mathrm{IV}^{17}$ & MBP & $\mathrm{IIII}^{10}$ \\
\hline $\mathrm{IL}-1 \beta$ & $\mathrm{IV}^{18}$ & MCP-1 & $\mathrm{III}^{10}$ \\
\hline IL-4 & $\mathrm{IV}^{18}$ & sCD40L & $\mathrm{IV}^{18}$ \\
\hline IL-6 & $\mathrm{IV}^{18}$ & Sulfatide & $\mathrm{IIII}^{19}$ \\
\hline IL-8 & $\mathrm{IIII}^{10}$ & $\mathrm{~T} \beta \mathrm{R}-\mathrm{II}$ & $\mathrm{IV}^{15}$ \\
\hline IL-10 & $\mathrm{IV}^{18}$ & TGF- $\beta 1$ & $\mathrm{IV}^{15}$ \\
\hline IL-17A & $\mathrm{IV}^{18}$ & TGF- $\beta 2$ & $\mathrm{IV}^{15}$ \\
\hline $\mathrm{IL}-21$ & $\mathrm{IV}^{18}$ & Transthyretin & $\mathrm{III}^{21}$ \\
\hline IL-22 & $\mathrm{IV}^{18}$ & YKL40 & $\mathrm{III}^{22}$ \\
\hline IL-31 & $\mathrm{IV}^{18}$ & & \\
\hline
\end{tabular}

approximately 74 years. These data led us to conclude that the patients included in our review are representative of the generally treated iNPH population. ${ }^{25}$ In total, 37 unique CSF biomarkers were analyzed within the studies. Of the 37 CSF biomarkers, 23 were only analyzed within single studies (see Table 1). These biomarkers will be discussed briefly below, and the remaining 14 biomarkers, analyzed in multiple studies, will be discussed in greater detail further along in this article.

\section{INTERLEUKINS (ILS)}

Interleukins are a group of cytokines that play a role in regulating immune response and inflammatory reactions. Both antiinflammatory (IL-4 and IL-10), and proinflammatory (IL-1 $\beta$, IL-6, IL-8, IL-17A, IL-21, IL-22, IL-31, IL-33) interleukins were investigated in the articles included in our review. Only IL-8 was directly compared between SR and SNR patients, and the levels were found to be not significantly different. ${ }^{10}$ Sosvorová ${ }^{18}$ found that IL-1 $\beta$, IL-6, and, interestingly, IL-10 were significantly elevated in iNPH patients versus normal controls. That study did not account for comorbid conditions that could cause an elevation of interleukins. However, the levels of these interleukins decreased significantly in SR patients during lumbar drainage procedures. Because of this, Sosvorová ${ }^{18}$ proposed that IL-1 $\beta$ and IL- 6 were elevated due to an inflammatory process occurring in the pathogenesis of iNPH and that IL-10 was possibly elevated as a normal body defense mechanism. However, all patients included in the study were classified as shunt responders, so their predictive value in differentiating SR patients from SNR patients cannot be determined. Further studies need to be done to determine the predictive value of interleukins in the workup of iNPH.

\section{Other Proinflammatory Cytokines}

Neuroinflammation and abnormal levels of CSF proinflammatory cytokines have been noted in various central nervous system diseases. ${ }^{26}$ Monocyte chemoattractant protein-1 (MCP-1) and soluble CD40 ligand (sCD40L) were each investigated in one article included in our review. MCP-1 levels were directly compared between SR and SNR patients, and the levels were not found to be significantly different. ${ }^{10} \mathrm{SCD} 40 \mathrm{~L}$ was included in an article in which all iNPH patients were classified as shunt responders, so the predictive value of sCD40L cannot be determined. ${ }^{18}$ However, no significant differences in sCD40L levels were found between iNPH patients and normal controls.

\section{Markers of Neuronal Damage}

As iNPH is a potentially reversible neurodegenerative disease, the presence of neuronal damage and the CSF biomarkers of such have been investigated in several studies..$^{9,10,19,27}$ Sulfatide and myelin basic protein (MBP) were each investigated in one article included in our review. Sulfatide is a lipid component of the myelin sheath and has been used as a marker of white matter degradation. $^{28} \mathrm{MBP}$ is a structural protein involved in the myelination of neurons in the central nervous system, and an increased CSF level is a well-established marker for myelination damage. $^{29}$ No statistically significant differences in sulfatide or MBP levels were found between SR and SNR patients. ${ }^{10,19}$

\section{Neuroprotective Proteins}

Neuroprotective proteins were investigated in three articles included in our review. Cystatin $\mathrm{C}$, lipocalin-type prostaglandin $\mathrm{D}_{2}$ synthase (L-PGDS), and transthyretin are proteins involved in amyloid beta $(\mathrm{A} \beta)$ metabolism and transport, and they protect neuronal cells from $A \beta$ toxicity and aggregation. ${ }^{30-32}$ In single studies, levels of L-PGDS, cystatin C, and transthyretin were found to be not significantly different between SR and SNR patients. $^{13,21}$ The physiological roles of transforming growth factor (TGF) and TGF beta receptor 2 (TBR-II) in the central nervous system are poorly understood, but they do exhibit neuroprotective functions. ${ }^{33}$ TGF- $\beta 1$, TGF- $\beta 2$, and TBR-II were investigated in one article in which all iNPH patients were classified as shunt responders, so the predictive value of these biomarkers cannot be determined. ${ }^{15}$ Levels of TGF- $\beta 1$ and TBR-II were significantly elevated in iNPH patients versus normal controls, and this warrants further investigation to determine their predictive value.

\section{OTHERS}

Homocysteine, chitinase-3-like protein 1 (YKL-40), and A $\beta 43$ were each investigated in single articles included in the present review. Homocysteine is an amino acid that has been shown to increase in a variety of neurological conditions, including multiple sclerosis, Parkinson's disease, and dementia. ${ }^{34}$ Homocysteine was investigated in one article in which all iNPH patients were classified as shunt responders, so the predictive value of these biomarkers cannot be determined. ${ }^{17}$ Levels of homocysteine were significantly elevated in iNPH patients versus normal controls and warrant further investigation to determine the predictive value of homocysteine. YKL-40 is a glycoprotein whose function is not fully understood but is associated with inflammatory processes. ${ }^{35}$ YKL-40 levels were directly compared between SR and SNR patients, and their levels were not found to be significantly different. ${ }^{22} \mathrm{~A} \beta 43$ is an amyloid beta peptide that is a key component of neuritic amyloid plaques. A $\beta 43$ levels were directly compared between SR and SNR patients, and levels were not found to be significantly different. ${ }^{20}$ Amyloid beta peptides are discussed further below.

The remaining 14 CSF biomarkers were analyzed in two or more studies and will be discussed further (see Table 2). 


\section{Table 2: CSF biomarkers analyzed in multiple studies}

\begin{tabular}{l|c|c|c|c}
\hline & \multicolumn{4}{|c}{ Quality of studies } \\
\hline Biomarker & Class I & Class II & Class III & Class IV \\
\hline A 388 & - & - & 2 & 1 \\
\hline A 440 & - & 1 & 4 & 2 \\
\hline A 442 & - & 1 & 4 & 2 \\
\hline sAPP & - & - & 1 & 2 \\
\hline aAPP $\alpha$ & - & - & 4 & 2 \\
\hline sAPP $\beta$ & - & - & 4 & 2 \\
\hline APL1 $\beta 25$ & - & - & 2 & - \\
\hline APL1 $\beta 27$ & - & - & 2 & - \\
\hline APLi $\beta 28$ & - & - & 2 & - \\
\hline Tau & - & 2 & 3 & 1 \\
\hline P-tau-181 & - & 1 & 3 & 2 \\
\hline NFL & - & - & 3 & - \\
\hline LRG & - & 1 & - & 2 \\
\hline TNF- $\alpha$ & - & - & 1 & 1 \\
\hline
\end{tabular}

\section{Ab38, Ab40, AND Ab42}

Amyloid beta $(A \beta)$ peptides are a key component of neuritic amyloid plaques, derived from amyloid precursor protein (APP), and are believed to trigger the pathogenesis of Alzheimer's disease (AD). Low CSF levels of A $\beta$ peptides, in particular A $\beta 42$, are strongly associated with AD. ${ }^{36}$ Due to the age of the affected population, 25 to $40 \%$ of iNPH patients will have comorbid AD pathology. ${ }^{37-39}$ In previous studies, less severe amyloid deposits correlated with better cognitive improvement after shunting in iNPH patients. ${ }^{40,41}$ Due to their roles as core CSF biomarkers for neurodegeneration, $\mathrm{A} \beta$ peptides are among the most studied biomarkers for iNPH.

In this review, $\mathrm{A} \beta 38$ was analyzed in one class $\mathrm{IV}^{13}$ and two class III articles, ${ }^{20,22} \mathrm{~A} \beta 40$ was analyzed in two class III articles, ${ }^{20,22}$ and $A \beta 42$ was analyzed in two class IV, ${ }^{13,16}$ four class III, ${ }^{10,19,20,22}$ and one class II article. ${ }^{24}$ In the studies included in our review, no statistically significant differences were found between SR and SNR patients for any of the A $\beta$ peptides. A study by Nakajima ${ }^{13}$ found that, with a cutoff value of $>3.58$, the $A \beta 38: A \beta 42$ ratio could predict postoperative cognitive improvement with a sensitivity of $77.8 \%$ and a specificity of $81 \%$. The same study found that a cutoff of $<14.6$ for the A 342 :p-tau ratio had a sensitivity of $76 \%$ and a specificity of $72.7 \% .^{13}$ However, that study only reported on postoperative cognitive improvement and did not report on improvements in gait or urinary function. Levels of $\mathrm{A} \beta$ peptides consistent with $\mathrm{AD}$ may have a role in predicting postoperative cognitive improvement, but the presence of these $\mathrm{A} \beta$ profiles does not definitively rule out iNPH patients from responding to a shunt procedure.

The available data do not support $\mathrm{A} \beta 38$, $\mathrm{A} \beta 40$, or $\mathrm{A} \beta 42$ individually as being reliable predictors of shunt responsiveness in iNPH patients. However, in combination with other CSF biomarkers, $\mathrm{A} \beta$ peptides (in particular, $\mathrm{A} \beta 42$ ), they may have prognostic value in the workup of iNPH.

\section{SAPP, SAPPA, AND SAPPB}

APP is a transmembrane protein that plays an integral role in a wide variety of neuronal functions. ${ }^{42}$ APP fragments, including $\mathrm{APP} \alpha$ and $\mathrm{APP} \beta$, have neuroprotective and neurotrophic functions, and cleavage of APP also produces A $\beta$ peptides. ${ }^{42}$ Levels of soluble APP (sAPP) and soluble APP fragments (sAPP $\alpha$ and sAPP $\beta$ ) can be measured in CSF samples. In this review, sAPP was analyzed in two class IV $^{13,16}$ and one class III article, ${ }^{20}$ SAPP $\alpha$ was analyzed in two class IV $^{13,16}$ and four class III articles, ${ }^{10,20-22}$ and SAPP $\beta$ was analyzed in two class IV ${ }^{13,16}$ and four class III articles. ${ }^{10,20-22}$ Levels of sAPP were not found to be significantly different in shunt responders versus nonresponders in any of the included articles.

In five of the included studies, sAPP $\beta$ levels were not found to be significantly different in SR versus SNR patients. ${ }^{10,13,20-22}$ However, one class III study found a very significant difference in sAPP $\beta$ levels. ${ }^{16}$ In that study, reported sAPP $\beta$ levels in shuntresponsive patients were significantly lower than those reported in all other included studies.

In one class III ${ }^{10}$ and one class IV article, ${ }^{16}$ sAPP $\alpha$ levels were significantly different between SR and SNR patients and had moderately accurate predictive ability. Using a cutoff value of $198 \mathrm{ng} / \mathrm{mL}$, Miyajima ${ }^{16}$ found that sAPP $\alpha$ levels had a sensitivity of $66.7 \%$ and a specificity of $82.9 \%$ in predicting postoperative cognitive outcomes. In the remaining three class III articles ${ }^{20-22}$ and one class IV article, ${ }^{13}$ sAPP $\alpha$ levels were not found to be significantly different. The available data do not support sAPP, sAPP $\alpha$, or sAPP $\beta$ levels as being reliable predictors of shunt responsiveness in iNPH patients.

\section{APL1в25, APL1в27, APL1в28}

Amyloid precursor-like protein $1 \beta$-derived (APL1 $\beta$ ) peptides are similar to sAPP-derived peptides in sequence and function. $^{43,44}$ APL1 $\beta$ peptides do not deposit in the brain, and APL1 $\beta 28$ has been proposed as a surrogate biomarker for A $\beta 42 .{ }^{45}$ In our review, APL1 $\beta 25$, APL1 $\beta 27$, and APL1 $\beta 28$ were each analyzed in two class III articles, ${ }^{20,22}$ neither of which found any significant difference in levels between SR and SNR patients. The available data do not support APL1 $\beta 25$, APL1 $\beta 27$, or APL1 $\beta 28$ levels as being reliable predictors of shunt responsiveness in iNPH patients.

\section{TAU AND P-TAU-181}

Tau is a structural protein that stabilizes microtubules and is abundant in the neurons of the central nervous system. CSF levels of tau protein and phosphorylated tau at threonine-181 (p-tau) are increased in patients with $\mathrm{AD},{ }^{36}$ and elevated CSF levels of tau are also found in such other neurodegenerative diseases as frontotemporal lobar degeneration and Creutzfeldt-Jakob disease. ${ }^{46}$ Due to their roles as core CSF biomarkers for neurodegeneration, tau and p-tau are among the most studied biomarkers for iNPH. In our review, tau was analyzed in one class IV, ${ }^{16}$ three class III, ${ }^{10,19,20}$ and two class II articles, ${ }^{23,24}$ and p-tau was analyzed in two class IV, ${ }^{13,16}$ three class III, ${ }^{10,19,20}$ and one class II article. ${ }^{24}$

Tau protein was not found to be significantly different in SR versus SNR patients in any of the included studies. However, in one class IV study ${ }^{16}$ and one class II study, ${ }^{23}$ patients with high tau levels tended toward shunt nonresponsiveness. 
Levels of p-tau were found to be significantly lower in two class IV studies, looking only at cognitive outcomes. Nakajima ${ }^{13}$ found that a p-tau cutoff of $\leq 22 \mathrm{pg} / \mathrm{mL}$ was able to predict positive postoperative cognitive outcomes with a sensitivity of $77.8 \%$ and a specificity of $71.4 \%$. That study did not report on improvements in gait or urinary function. In the remaining three class III articles, p-tau levels were not significantly different in SR versus SNR patients. Levels of tau and p-tau consistent with AD may play a role in predicting lack of postoperative cognitive improvement; however, the presence of these $\mathrm{AD}$ profiles does not definitively rule out iNPH patients from responding to a shunt procedure. Similar to the abovementioned $\mathrm{A} \beta$ peptides, the majority of studies investigating tau and $\mathrm{p}$-tau did not account for comorbid conditions, such as AD, which could affect the CSF levels of these biomarkers. Due to the age of the affected population, $25-40 \%$ of iNPH patients will have comorbid AD pathologies ${ }^{37-39}$ that cause abnormal levels of A $\beta$ peptides, tau, and p-tau. Including these patients in analysis limits the ability of studies to determine whether abnormalities in these biomarkers are directly associated with the iNPH disease process. Though as discussed later on in this article, SR iNPH can exist concurrently with AD, and including these patients in analysis may yield results of greater real-world clinical relevance.

The available data do not support tau or p-tau, individually, as being reliable predictors of shunt responsiveness in iNPH patients. However, in combination with other CSF biomarkers, tau and p-tau may have prognostic value in the workup of iNPH.

\section{NFL}

Neurofilament light protein (NFL) is a major structural protein of axons, and it has been shown that NFL levels can be used as a marker of neuronal damage and neurodegeneration. ${ }^{47,48}$ Levels of NFL have previously been reported to correlate with shunt responsiveness. ${ }^{9}$ In one study, NFL levels greater than $640 \mathrm{mg} / \mathrm{L}$ were identified as having a specificity of $100 \%$ but a low sensitivity of $17 \%$ for determining a positive outcome after shunt surgery. ${ }^{9}$ That study, however, combined both secondary and idiopathic NPH in the analysis, and the diagnostic values found cannot be generalized to patients with probable iNPH.

NFL was analyzed in three class III articles included in our review. ${ }^{10,19,22}$ In a study by Pyykko, ${ }^{10}$ the levels of NFL were significantly higher in SNR versus SR patients. A study by AgrenWilsson ${ }^{19}$ found that, although NFL levels were not significantly different in SR versus SNR patients, SNR patients tended toward higher NFL levels. Higher NFL concentrations were found in iNPH patients with more severe symptoms, in line with its role as a marker of neuronal damage. ${ }^{19}$ The remaining study by Jeppsson ${ }^{22}$ found no significant differences in NFL levels. The available data suggest that NFL may have prognostic value in the evaluation of iNPH, though no study included in our review reported any predictive value.

\section{LRG}

Leucine-rich alpha-2-glycoprotein (LRG) is an inflammationinduced protein. It has been proposed as a biomarker for a variety of diseases, including ulcerative colitis, ovarian cancer, and pancreatic cancer. ${ }^{48-50}$ However, studies investigating its use as a CSF biomarker for neurodegenerative diseases have been minimal.

LRG was analyzed in two class IV articles ${ }^{14,15}$ and one class II article $^{23}$ included in our review. In one of the only class II studies included herein, Nakajima ${ }^{23}$ found that elevated LRG levels correlate strongly with shunt responsiveness. Using receiver operating characteristic (ROC) analysis, his study found that, using an LRG cutoff of $\geq 67 \mathrm{ng} / \mathrm{mL}$, SR and SNR patients were able to be differentiated with a sensitivity of $81.6 \%$ and a specificity of $78.6 \%$. Using the same data, an LRG cutoff of $\geq 20 \mathrm{ng} / \mathrm{mL}$ was able to predict shunt response with a sensitivity of $100 \%$ and a specificity of $54.5 \%$ (i.e., $100 \%$ of responsive patients would be classified as SR, and $54.5 \%$ of SNR patients would be classified as SNR). The remaining class IV studies by $\mathrm{Li}^{14,15}$ contained relatively few iNPH patients (15 and 21, respectively), and all were classified as SR. Because all iNPH patients were classified as SR, these studies do not directly add to determining the predictive value of LRG, though they do aid in evaluation of the remaining study by Nakajima. ${ }^{23}$ The studies investigating LRG did not account for comorbid conditions that could cause an elevated LRG. However, the studies by $\mathrm{Li}^{14,15}$ found that levels of LRG were significantly elevated in iNPH patients compared to age-related controls, suggesting that the LRG elevation is due to the iNPH disease process.

The mean LRG levels in SR patients found in the studies by $\mathrm{Li}^{14,15}$ are approximately two orders of magnitude lower than those found by Nakajima ${ }^{23}$ at 1.14 and $1.05 \mathrm{ng} / \mathrm{mL}$ versus 96.8 $\mathrm{ng} / \mathrm{mL}$, respectively. This difference could be explained through the studies using different, nonstandardized enzyme-linked immunosorbent assays (ELISAs), or due to an analysis error. Due to this difference, no direct comparison can be made between these studies. The available data suggest that LRG levels may have prognostic value in the evaluation of iNPH, though additional high-quality research is required.

\section{TNF- $\alpha$}

Tumor necrosis factor alpha (TNF- $\alpha)$ is a proinflammatory cytokine that is central in a variety of disease states, including rheumatoid arthritis, psoriasis, inflammatory bowel disease, systemic infection, and ischemia-reperfusion injury. ${ }^{52,53}$ With abnormal levels of proinflammatory cytokines being present in various neurological diseases, $\mathrm{TNF}-\alpha$ has been investigated in numerous studies of iNPH. ${ }^{8,10,18,54} \mathrm{TNF}-\alpha$ was analyzed in one class IV $\mathrm{IV}^{18}$ and one class III article ${ }^{10}$ included in our review.

Pyykko ${ }^{10}$ found no significant differences in TNF- $\alpha$ levels between SR and SNR patients. In a study by Sosvorová, ${ }^{18}$ all iNPH patients were classified as shunt responders. However, no significant differences in TNF- $\alpha$ levels were found between iNPH patients and normal controls. The available data do not support TNF- $\alpha$ levels as being reliable predictors of shunt responsiveness in iNPH patients.

\section{DiscUSSION}

The purpose of this review was to summarize the current state of research into using preoperative CSF biomarkers to predict treatment response in iNPH patients. Through our review, we found that the available evidence is greatest for the use of $\mathrm{A} \beta 42$, tau, p-tau, NFL, and LRG in predicting shunt response in iNPH patients. There is minimal evidence for the use of TGF- $\beta 1$, TBRII, homocysteine, and interleukins (in particular IL-1 $\beta$, IL-6, and IL-10). However, the available evidence suggests that these biomarkers warrant further investigation. We found that there was no available evidence for the use of $\mathrm{A} \beta 38, \mathrm{~A} \beta 40, \mathrm{~A} \beta 43$, APL1 $\beta 25$, 
APL1 $\beta 27$, APL1 $\beta 28$, sAPP, aAPP $\alpha$, sAPP $\beta$, TNF- $\alpha$, MCP-1, sCD40L, sulfatide, MBP, L-PGDS, cystatin C, transthyretin, TGF- $\beta 2$, and YKL- 40 . There are other CSF biomarkers that are commonly investigated in other neurological conditions that have not been investigated for iNPH. These include alpha-synuclein ( $\alpha$-synuclein), interferon gamma (IFN- $\gamma$ ), neuron-specific enolase (NSE), and visinin-like protein-1 (VILIP-1). Alpha-synuclein is a major constituent of Lewy bodies and has been investigated widely as a biomarker for Parkinson's disease. ${ }^{55,56}$ IFN- $\gamma$ is a proinflammatory cytokine, and, as discussed above, abnormal levels of CSF proinflammatory cytokines have been noted in various central nervous system diseases. ${ }^{26}$ NSE is a glycolytic enzyme found in neuronal and neuroendocrine tissues and has been investigated as a marker of neurodegeneration in Alzheimer's disease. ${ }^{36}$ VILIP-1 is a neuronal calcium sensor protein and has also been investigated as a marker of neurodegeneration in Alzheimer's disease. ${ }^{36}$

It is expected that no single CSF biomarker will be able to reliably predict shunt-responsive patients with high sensitivity and specificity. This is because the lack of treatment response in patients is likely caused by many different pathologies, including progressed and irreversible iNPH, or such other concurrent neurodegenerative diseases as Alzheimer's disease, Parkinson's disease, or dementia with Lewy bodies. It is also not yet known whether iNPH represents a distinct clinicopathological entity or rather a heterogeneous syndrome. A combination approach, such as that used by Nakajima, ${ }^{23}$ will likely increase the clinical value of biomarkers in predicting shunt responsiveness. Nakajima combined cutoff values for both LRG and tau to maximize sensitivity and specificity. Because of the potential for significant improvements in quality of life with shunt surgery for patients with SR iNPH, it is important that patients who would otherwise be good surgical candidates, not be refused shunt surgery based on false-negative biomarker analysis. For this reason, sensitivity of biomarker profiles should be prioritized over specificity in future studies (see Table 3).

Through this review, it was found that iNPH patients with biomarker profiles consistent with $\mathrm{AD}$ tended toward lower postoperative cognitive improvement, which is not an unexpected result. Decreased CSF levels of A $\beta 42$ and increased CSF levels of tau and p-tau are strongly associated with $\mathrm{AD} .^{36}$ The sensitivities

Table 3: Summary of biomarker evidence

\begin{tabular}{l|l|l|l}
\hline $\begin{array}{l}\text { Greatest } \\
\text { evidence }\end{array}$ & $\begin{array}{l}\text { Warrants further } \\
\text { investigation }\end{array}$ & $\begin{array}{l}\text { No available } \\
\text { evidence }\end{array}$ & $\begin{array}{l}\text { Has not been } \\
\text { investigated }\end{array}$ \\
\hline A $\beta 42$ & TGF- $\beta 1$ & A $\beta 38$, A $\beta 40$, & $\alpha$-synuclein \\
Tau & TBR-II & A $\beta 43$ & IFN- $\gamma$ \\
P-tau & Homocysteine & APL1 $\beta 25$, & NSE \\
NFL & Interleukins (in particular & APL1 $\beta 27$, & VILIP-1 \\
LRG & IL-1 $\beta$, IL-6, IL-10) & APL1 $\beta 28$ & \\
& & sAPP, aAPP $\alpha$, & \\
& & sAPP $\beta$ & \\
& & TNF- $\alpha$ & \\
& & MCP-1 & \\
& & sCD40L & \\
& & Sulfatide & \\
& & MBP & \\
& & L-PGDS & \\
& & Cystatin C & \\
& & Transthyretin & \\
& & TGF- $\beta 2$ & \\
& & YKL-40 & \\
& &
\end{tabular}

and specificities of these biomarker profiles approached $80 \%$ in predicting postoperative cognitive improvement in iNPH patients. It is important to note, however, that iNPH patients can exhibit postoperative cognitive improvement, as well as gait and urinary symptom improvement, even in the face of biomarkers consistent with $\mathrm{AD}$, confirming that $\mathrm{iNPH}$ is a syndrome that can exist with $\mathrm{AD}$

A limitation of our review article is that the majority of available data are presented such that predictive values cannot be calculated. Only two class IV studies ${ }^{13,16}$ and one class II study ${ }^{23}$ included prognostic sensitivities and specificities. Studies that report whether biomarkers are statistically significant or not between SR and SNR patients do have great value in guiding future research. However, future studies should focus on determining and verifying the predictive values (specificity/sensitivity) of these CSF biomarkers, so that they might be of clinical value. The majority of the included studies had the primary purpose of determining biomarker value in the differential diagnosis of iNPH. Many of the biomarkers that showed no predictive value in determining shunt responsiveness were shown to be of value in the differential diagnosis of iNPH, though these data were not analyzed in this review. Another limitation of our review article is that the included studies used varying definitions to determine shunt responsiveness, making it difficult to directly compare the results of studies. In four of the studies included in our review, all iNPH patients were classified as shunt-responsive. ${ }^{14,15,17,18}$ These studies do not directly add to determining the predictive value of the biomarkers analyzed, though, as discussed in the analysis of LRG above, they can aid in the evaluation and validation of the remaining studies.

Current studies looking into iNPH biomarkers have been limited by their small numbers. Common to all studies evaluating prognostic outcomes of iNPH shunt patients is that the number of patients who are shunt-nonresponsive is often too low to draw any definite conclusions. This was particularly relevant for our review, as 8 of the 13 included studies had 10 or fewer shunt-nonresponsive patients. Multiple research networks, including the Adult Hydrocephalus Clinical Research Network in North America, are working on developing CSF biobanks for adult hydrocephalus patients. Future studies into CSF biomarkers should take advantage of such biobanks so as to achieve greater numbers, avoid single-center bias, and achieve greater reproducibility. This will be especially important when conducting research into the relationship between CSF biomarkers and shunt responsiveness where single-site/single-surgeon bias may occur.

\section{CONCLUSIONS}

A $\beta 42$, tau, p-tau, NFL, and LRG have the greatest amount of evidence for their predictive value in determining shunt responsiveness in iNPH patients. There is minimal evidence for the use of TGF- $\beta 1$, TBR-II, homocysteine, and interleukins (in particular IL-1 $\beta$, IL-6, and IL-10). However, the available evidence suggests that these biomarkers warrant further investigation. Future research should be guided by, but not limited to, these biomarkers. Future studies should focus on determining and verifying the predictive value (specificity/sensitivity) of these CSF biomarkers so that they may be of clinical value. Importantly, SR iNPH may coexist with biomarker profiles consistent with AD. 


\section{Disclosures}

Tyler Pfanner and Stephanie Borchert have nothing to disclose. Dr. Henri-Bhargava reports grants from Lilly and Astrazeneca via Paraxel, from Boehringer Ingelheim, from Roche, and from TauRx; and personal fees from Merck and the Tapestry Foundation; outside the submitted work.

\section{Statement of Authorship}

Study concept and design: TP, AHB. Literature review: TP, AHB, SB. Interpretation of data: TP, AHB. Drafting of manuscript and revisions: TP, AHB.

\section{SUPPLEMENTARY MATERIAL}

To view the supplementary materials for this article, please visit https://doi.org/10.1017/cjn.2017.251

\section{REFERENCES}

1. Ishikawa M. Clinical guidelines for idiopathic normal pressure hydrocephalus. Neurol Med Chir (Tokyo). 2004;44 (4):222-3.

2. Relkin N, Marmarou A, Klinge P, Bergsneider M, Black PM. Diagnosing idiopathic normal-pressure hydrocephalus. Neurosurgery. 2005;57(3 Suppl):S4-16; discussion ii-v.

3. Mori E, Ishikawa M, Kato T, et al. Guidelines for management of idiopathic normal pressure hydrocephalus: second edition. Neurol Med Chir (Tokyo). 2012;52(11):775-809.

4. Toma A, Papadopoulos M, Stapleton S, Kitchen N, Watkins L. Systematic review of the outcome of shunt surgery in idiopathic normal-pressure hydrocephalus. Acta Neurochir (Wien). 2013;155(10):1977-80.

5. Halperin JJ, Halperin JJ, Kurlan R, Schwalb JM, Cusimano MD, Gronseth G, Gloss D. Practice guideline. Idiopathic normal pressure hydrocephalus: response to shunting and predictors of response. Report of the Guideline Development, Dissemination, and Implementation Subcommittee of the American Academy of Neurology. Neurology. 2015;85(23):2063-71.

6. Virhammar J, Laurell K, Cesarini KG, Larsson E. Preoperative prognostic value of MRI findings in 108 patients with idiopathic normal pressure hydrocephalus. AJNR Am J Neuroradiol. 2014;35(12):2311-8.

7. Kojoukhova M, Koivisto A, Korhonen R, et al. Feasibility of radiological markers in idiopathic normal pressure hydrocephalus. Acta Neurochir (Wien). 2015;157(10):1709-19.

8. Lee J, Park D, Back D, et al. Comparison of cerebrospinal fluid biomarkers between idiopathic normal pressure hydrocephalus and subarachnoid hemorrhage-induced chronic hydrocephalus: a pilot study. Med Sci Monit. 2012;18(12):PR19-25.

9. Tullberg M, Blennow K, Månsson J, Fredman P, Tisell M, Wikkelsö C. Cerebrospinal fluid markers before and after shunting in patients with secondary and idiopathic normal pressure hydrocephalus. Cerebrospinal Fluid Res. 2008;5(1):9. https://www.ncbi.nlm.nih. gov/pmc/articles/PMC2387137/. Accessed August 21, 2017.

10. Pyykkö OT, Lumela M, Rummukainen J, et al. Cerebrospinal fluid biomarker and brain biopsy findings in idiopathic normal pressure hydrocephalus. PLoS One. 2014;9(3):e91974. https://www.ncbi. nlm.nih.gov/pmc/articles/PMC3956805/. Accessed August 21, 2017.

11. Djukic M, Spreer A, Lange P, Bunkowski S, Wiltfang J, Nau R. Small cisterno-lumbar gradient of phosphorylated tau protein in geriatric patients with suspected normal pressure hydrocephalus. Fluids Barriers CNS. 2016;13(1):15. https://www.ncbi.nlm.nih. gov/pmc/articles/PMC5007695/. Accessed August 21, 2017.

12. American Academy of Neurology. Clinical Practice Guideline Process Manual. St. Paul, MN: The American Academy of Neurology; 2011.

13. Nakajima M, Miyajima M, Ogino I, et al. Cerebrospinal fluid biomarkers for prognosis of long-term cognitive treatment outcomes in patients with idiopathic normal pressure hydrocephalus. J Neurol Sci. 2015;357(1-2):88-95.

14. Li X, Miyajima M, Mineki R, Taka H, Murayama K, Arai H. Analysis of potential diagnostic biomarkers in cerebrospinal fluid of idiopathic normal pressure hydrocephalus by proteomics. Acta Neurochir (Wien). 2006;148(8):859-64.

15. Li X, Miyajima M, Jiang C, Arai H. Expression of TGF-betas and TGF-beta type II receptor in cerebrospinal fluid of patients with idiopathic normal pressure hydrocephalus. Neurosci Lett. 2007;413(2):141-4.

16. Miyajima M, Nakajima M, Ogino I, Miyata H, Motoi Y, Arai H. Soluble amyloid precursor protein $\alpha$ in the cerebrospinal fluid as a diagnostic and prognostic biomarker for idiopathic normal pressure hydrocephalus. Eur J Neurol. 2013;20(2):236-42.

17. Sosvorová L, Besták J, Bicíková $\mathrm{M}$, et al. Determination of homocysteine in cerebrospinal fluid as an indicator for surgery treatment in patients with hydrocephalus. Physiol Res. 2014;63 (4):521-7.

18. Sosvorová L, Vcelak J, Mohapl M, Vitku J, Bicikova M, Hampl R. Selected pro- and anti-inflammatory cytokines in cerebrospinal fluid in normal pressure hydrocephalus. Neuro Endocrinol Lett. 2014;35(7):586-93.

19. Agren-Wilsson A, Lekman A, Sjöberg W, et al. CSF biomarkers in the evaluation of idiopathic normal pressure hydrocephalus. Acta Neurol Scand. 2007;116(5):333-9.

20. Moriya M, Miyajima M, Nakajima M, Ogino I, Arai H. Impact of cerebrospinal fluid shunting for idiopathic normal pressure hydrocephalus on the amyloid cascade. PLoS One. 2015;10(3):e0119973. https://www.ncbi.nlm.nih.gov/pmc/articles/ PMC4379026/. Accessed August 21, 2017.

21. Laiterä T, Kurki MI, Pursiheimo J, et al. The expression of transthyretin and amyloid- $\beta$ protein precursor is altered in the brain of idiopathic normal pressure hydrocephalus patients. J Alzheimers Dis. 2015;48(4):959-68.

22. Jeppsson A, Höltta M, Zetterberg H, Blennow K, Wikkelsø C, Tullberg M. Amyloid mis-metabolism in idiopathic normal pressure hydrocephalus. Fluids Barriers CNS. 2016;13(1): 13. https://www.ncbi.nlm.nih.gov/pmc/articles/PMC4967298/. Accessed August 21, 2017.

23. Nakajima M, Miyajima M, Ogino I, et al. Leucine-rich $\alpha$-2-glycoprotein is a marker for idiopathic normal pressure hydrocephalus. Acta Neurochir (Wien). 2011;153(6):1339-46.

24. Luikku A, Hall A, Nerg O, et al. Multimodal analysis to predict shunt surgery outcome of 284 patients with suspected idiopathic normal pressure hydrocephalus. Acta Neurochir (Wien). 2016;158 (12):2311-9.

25. Williams M, Malm J. Diagnosis and treatment of idiopathic normal pressure hydrocephalus. Continuum (Minneap Minn). 2016;22 (2 Dementia):579-99.

26. Chakraborty S, Kaushik DK, Gupta M, Basu A. Inflammasome signaling at the heart of central nervous system pathology. J Neurosci Res. 2010;88(8):1615-31.

27. Tullberg $\mathrm{M}$, Blennow $\mathrm{K}$, Månsson JE, Fredman $\mathrm{P}$, Tisell $\mathrm{M}$, Wikkelsö C. Ventricular cerebrospinal fluid neurofilament protein levels decrease in parallel with white matter pathology after shunt surgery in normal pressure hydrocephalus. Eur J Neurol. 2007;14(3):248-54.

28. Fredman P, Wallin A, Blennow K, Davidsson P, Gottfries CG, Svennerholm L. Sulfatide as a biochemical marker in cerebrospinal fluid of patients with vascular dementia. Acta Neurol Scand. 1992;85(2):103-6.

29. Whitaker JN. Myelin basic protein in cerebrospinal fluid and other body fluids. Mult Scler. 1998;4(1):16-21.

30. Kanekiyo T, Ban T, Aritake K, et al. Lipocalin-type prostaglandin D synthase/beta-trace is a major amyloid beta-chaperone in human cerebrospinal fluid. Proc Natl Acad Sci U S A. 2007;104 (15):6412-7.

31. Costa R, Ferreira-da-Silva R, Saraiva MJ, Cardoso I. Transthyretin protects against A-beta peptide toxicity by proteolytic cleavage of the peptide: a mechanism sensitive to the Kunitz protease inhibitor. PLoS One. 2008;3(8):e2899. https://www.ncbi. nlm.nih.gov/pmc/articles/PMC2483353/. Accessed August 21, 2017. 
32. Tizon B, Ribe EM, Mi W, Troy CM, Levy E. Cystatin C protects neuronal cells from amyloid-beta-induced toxicity. J Alzheimers Dis. 2010;19(3):885-94

33. Dobolyi A, Vincze C, Pál G, Lovas G. The neuroprotective functions of transforming growth factor beta proteins. Int J Mol Sci. 2012;13(7):8219-58

34. Ansari R, Mahta A, Mallack E, Luo JJ. Hyperhomocysteinemia and neurologic disorders: a review. J Clin Neurol. 2014;10(4):281-8.

35. Rathcke CN, Vestergaard H. YKL-40: an emerging biomarker in cardiovascular disease and diabetes. Cardiovasc Diabetol. 2009;8 (1):61. https://www.ncbi.nlm.nih.gov/pmc/articles/PMC2789050/. Accessed August 21, 2017.

36. Olsson B, Olsson C, Lautner R, et al. CSF and blood biomarkers for the diagnosis of Alzheimer's disease: a systematic review and meta-analysis. Lancet Neurol. 2016;15(7):673-84.

37. Cabral D, Beach TG, Vedders L, et al. Frequency of Alzheimer's disease pathology at autopsy in patients with clinical normal pressure hydrocephalus. Alzheimers Dement. 2011;7(5):509-13.

38. Bech-Azeddine R, Høgh P, Juhler M, Gjerris F, Waldemar G. Idiopathic normal-pressure hydrocephalus: clinical comorbidity correlated with cerebral biopsy findings and outcome of cerebrospinal fluid shunting. J Neurol Neurosurg Psychiatry. 2007;78 (2): $157-61$.

39. Hamilton R, Patel S, Lee EB, et al. Lack of shunt response in suspected idiopathic normal pressure hydrocephalus with Alzheimer disease pathology. Ann Neurol. 2010;68(4):535-40.

40. Hiraoka K, Narita W, Kikuchi H, et al. Amyloid deposits and response to shunt surgery in idiopathic normal-pressure hydrocephalus. J Neurol Sci. 2015;356(1-2):124-8.

41. Koga S. Elucidating the etiology of normal pressure hydrocephalus (NPH) and the spectrum of surgically treatable dementias. Am Assoc Neurol Surg. 2010;113(2):A418.

42. Turner PR, O'Connor K, Tate WP, Abraham WC. Roles of amyloid precursor protein and its fragments in regulating neural activity, plasticity and memory. Progr Neurobiol. 2003;70(1):1-32.

43. Coulson EJ, Paliga K, Beyreuther K, Masters CL. What the evolution of the amyloid protein precursor supergene family tells us about its function. Neurochem Int. 2000;36(3):175-84.

44. Jacobsen KT, Iverfeldt K. Amyloid precursor protein and its homologues: a family of proteolysis-dependent receptors. Cell Mol Life Sci. 2009;66(14):2299-318.

45. Yanagida K, Okochi M, Tagami S, et al. The 28-amino acid form of an APLP1-derived A $\beta$-like peptide is a surrogate marker for $\mathrm{A} \beta 42$ production in the central nervous system. EMBO Mol Med. 2009;1(4):223-35.

46. van Harten AC, Kester MI, Visser P, et al. Tau and p-tau as CSF biomarkers in dementia: a meta-analysis. Clin Chem Lab Med. 2011;49(3):353-66.

47. Rosengren LE, Karlsson JE, Karlsson JO, Persson LI, Wikkelsø C. Patients with amyotrophic lateral sclerosis and other neurodegenerative diseases have increased levels of neurofilament protein in CSF. J Neurochem. 1996;67(5):2013-8.

48. Gisslén M, Price RW, Andreasson U, et al. Plasma concentration of the neurofilament light protein (NFL) is a biomarker of CNS injury in HIV infection: a cross-sectional study. EBioMedicine. 2016;3:135-40.

49. Serada S, Fujimoto M, Terabe F, et al. Serum leucine-rich alpha-2 glycoprotein is a disease activity biomarker in ulcerative colitis. Inflamm Bowel Dis. 2012;18(11):2169-79.

50. Andersen J, Boylan K, Jemmerson R, et al. Leucine-rich alpha2-glycoprotein-1 is upregulated in sera and tumors of ovarian cancer patients. J Ovarian Res. 2010; 3(1):21. https://www.ncbi.nlm.nih. gov/pmc/articles/PMC2949730/. Accessed August 21, 2017.

51. Kakisaka T, Kondo $\mathrm{T}$, Okano $\mathrm{T}$, et al. Plasma proteomics of pancreatic cancer patients by multi-dimensional liquid chromatography and two-dimensional difference gel electrophoresis (2D-DIGE): up-regulation of leucine-rich alpha-2-glycoprotein in pancreatic cancer. J Chromatogr B Analyt Technol Life Sci. 2007;852(1):257-67.

52. Strieter R, Kunkel S, Bone R. Role of tumor necrosis factor-alpha in disease states and inflammation. Crit Care Med. 1993;21(10 Suppl):S447-63.

53. Esposito E, Cuzzocrea S. TNF-alpha as a therapeutic target in inflammatory diseases, ischemia-reperfusion injury and trauma. Curr Med Chem. 2009;16(24):3152-67.

54. Leinonen V, Menon LG, Carroll RS, et al. Cerebrospinal fluid biomarkers in idiopathic normal pressure hydrocephalus. Int $\mathbf{J}$ Alzheimers Dis. 2011: 1-6.

55. Schulz-Schaeffer WJ. The synaptic pathology of alpha-synuclein aggregation in dementia with Lewy bodies, Parkinson's disease and Parkinson's disease dementia. Acta Neuropathol. 2010;120 (2):131-43.

56. Malek N, Swallow D, Grosset KA, Anichtchik O, Spillantini M, Grosset DG.. Alpha-synuclein in peripheral tissues and body fluids as a biomarker for Parkinson's disease: a systematic review. Acta Neurol Scand. 2014;130(2):59-72. 